\title{
Formación de lectores en bachillerato mediante la lectura recreativa de textos narrativos tradicionales'
}

\author{
Readers Training in High School through the Recreational Reading of \\ Traditional Narrative Texts
}

\author{
HUGO ANDRÉS ROMERO VALDÉS \\ MARIO MIGUEL OJEDA RAMÍREZ \\ MARÍA CRISTINA DÍAZ GONZÁLEZ
}

Universidad Veracruzana

México

mojeda@uv.mx

(Recibido: I8-O7-20I7; aceptado: OI-O8-2OI8)

Resumen. Este artículo expone la pertinencia de utilizar narraciones tradicionales mexicanas como materiales para promocionar la lectura en públicos diversos. Después de hacer una revisión de antecedentes y dar una serie de pautas teóricas y metodológicas, se reporta una intervención que consistió en un taller de lectura con adultos en una escuela de bachilleres en la ciudad de Xalapa, capital del estado de Veracruz, México. El trabajo se realizó durante ocho sesiones extracurriculares en el mismo plantel educativo. Se comentan los métodos de evaluación de la estrategia, así como los resultados de la intervención. Se trata de una experiencia afortunada de promoción de la lectura en un espacio educativo.

Palabras clave: promoción de la lectura; narración tradicional; adultos, intervención cultural.
Abstract. This article presents the pertinence of using traditional Mexican narratives as materials to promote reading in diverse audiences. After reviewing the background and giving a series of theoretical and methodological guidelines, we report an intervention that consisted of an adult reading workshop at a high school in the city of Xalapa, capital of the state of Veracruz, Mexico. The work was done during eight extracurricular sessions in the same educational establishment. The methods of evaluation of the strategy, as well as the results of the intervention, are discussed. It is a fortunate experience of promoting reading in an educational space.

Keywords: reading promotion; traditional narration; adults; cultural intervention

\footnotetext{
${ }^{\text {I }}$ Para citar este artículo: Romero Valdés, Hugo Andrés; Ojeda Ramírez, Mario Miguel y Díaz González, María Cristina (20I9). Formación de lectores en bachillerato mediante la lectura recreativa de textos narrativos tradicionales. Alabe 19. [www.revistaalabe.com] DOI: IO.I5645/Alabe2OI9.I9.3
} 


\section{Introducción}

En los últimos años la literatura tradicional de México ha sido objeto de numerosos estudios desde diferentes disciplinas y es tema frecuente de análisis en distintos foros académicos. Asimismo ciertos contenidos relacionados con la literatura de tradición oral se abordan en los programas de estudio de español y de literatura en la primaria, la secundaria y el bachillerato. Sin embargo, no siempre se utilizan los mejores ejemplos de ésta como materiales de lectura entre los niños, adolescentes y jóvenes. A veces esto sucede porque los docentes desconocen la existencia de publicaciones novedosas sobre literatura tradicional de México y eligen textos que proceden de otras culturas. En el caso particular de la educación media superior, conviene hacer esta pregunta: ¿por qué no sacarle mayor partido a la narrativa tradicional mexicana para hacer promoción de la lectura en un taller extracurricular dentro del actual plan de estudios de bachillerato de Veracruz?

La Dirección General de Bachillerato del Estado de Veracruz coordina el trabajo de las modalidades escolarizada y mixta. En la primera, los alumnos pueden llevarse hasta tres asignaturas a examen extraordinario porque en el momento que acumulan cuatro extraordinarios deben continuar sus estudios en la modalidad mixta. Asimismo esta opción es demandada por estudiantes que trabajan entre semana y sólo pueden asistir a clases los sábados. Es así como se entiende que la modalidad mixta atiende por igual a grupos integrados por adolescentes, jóvenes y adultos. En este contexto, el profesor que busca realizar actividades de promoción de la lectura con un alumnado tan heterogéneo tiene frente a sí un reto considerable. Una de las primeras interrogantes que vienen a la mente del maestro es el tipo de materiales de lectura que pueda ser del agrado de un público tan diverso como el de una modalidad mixta. La narrativa tradicional de México es una buena alternativa para promocionar la lectura por varias razones entre las que destacan: su brevedad, su riqueza cultural, su lenguaje accesible y los diferentes temas que abarca.

Este trabajo se basa en el proyecto de intervención que realizó el primer autor como parte de su proceso formativo en la Especialización en Promoción de la Lectura, un programa de posgrado de la Universidad Veracruzana, siguiendo los lineamientos establecidos por los coautores. La propuesta de intervención fue sometida a los diferentes ámbitos colegiados y se efectuó de noviembre de 2015 a febrero de 2016 en la Escuela de Bachilleres Modalidad Mixta Veracruz, en la ciudad de Xalapa. El artículo que aquí se presenta se deriva del trabajo recepcional sometido y defendido exitosamente en marzo de 2OI7. El artículo está integrado por siete apartados. El primero expone una revisión del estado de la cuestión y el segundo es una nota sobre los fundamentos teóricos; después, en el tercero y cuarto, se describe el contexto de la intervención así como los objetivos y la estrategia metodológica seguida; posteriormente se narra la intervención realizada, para dar lugar a los resultados, discusión y conclusiones. 


\section{Revisión de algunos antecedentes}

La naturaleza del proyecto de intervención remitió a la búsqueda de materiales relacionados con la lectura recreativa, el arte de contar historias y la promoción de la lectura. A continuación se incluye un esbozo bibliográfico sobre estos temas.

La lectura recreativa ha sido abordada por numerosos autores. Dentro de un contexto escolar, Sánchez Amador y otros (I994) afirman que la lectura recreativa proporciona placer y el lector tiene libertad para seleccionar lo que desea leer. En este mismo sentido, Kohan (I999) distingue entre lectura indirecta y lectura directa. La primera toma al libro como objeto y es utilizada como medio para aprender. Algunos expertos la llaman lectura utilitaria. La segunda permite tener una experiencia análoga a la de los sueños o a un viaje. Se efectúa en un ambiente de libertad. También se le conoce como lectura recreativa. En consonancia con lo anterior, Chambers (2007) explica que quien siente placer por la lectura reacciona de dos maneras diferentes: quiere experimentar otra vez regocijo leyendo el mismo libro, otros materiales de dicho autor o más textos de temáticas similares. Del mismo modo, no puede evitar hablarle a alguien más sobre la obra leída. Sin embargo, la lectura recreativa es muy poco trabajada en los niveles educativos: básico y medio. En relación con estos argumentos, Gambrell (2007) sostiene que la lectura recreativa es aquella que proporciona placer y gozo sin importar que se trate de ficción o no, de poesía o de cualquier otro tipo de género de lectura. Asimismo postula los principios de la lectura por placer, en los cuales el maestro es presentado como modelo, guía y motivador de la lectura frente a sus alumnos. En una experiencia diferente, Gladwin y Goulding (2OI2) explican que el término lectura recreativa se ha definido como aquella que realizamos libremente y que proporciona satisfacción al lector. Este concepto forma parte de una investigación desarrollada en un grupo de bibliotecas universitarias del Reino Unido. Los resultados de la misma evidencian que la promoción de la lectura recreativa en estos centros se ha incrementado por medio de acciones concretas.

Con respecto del arte de contar historias se localizaron tres experiencias exitosas que brindan muchas estrategias susceptibles de llevarse a cabo en un taller de promoción de la lectura dirigido a un público de bachilleres. Hanson (2005) comenta los resultados obtenidos por un grupo de maestros bibliotecarios que han ayudado a niños y jóvenes a desarrollar esta habilidad mediante ejercicios de narración oral ante el grupo escolar y en la familia. Entre los múltiples beneficios de narrar historias en el alumnado se consideran los siguientes: incremento de la seguridad personal, fluidez lectora y respeto por los demás. Asimismo Jackson (2007) da cuenta de un proyecto de contar historias en el sur de la Florida que involucra a distintas generaciones desde niños hasta adultos mayores, donde los recuerdos se transforman en distintos tipos de narraciones, incluidos los relatos tradicionales. Por último, Castro (2008) realiza un estudio pormenorizado de la narración oral en el cual expone una interesante caracterización del narrador rural y el narrador urbano. Existe un sano equilibrio en el oficio desempeñado por ambos. Ninguno de los dos es superior al otro. Cada uno es necesario en su contexto particular. 
En lo que se refiere a la promoción de la lectura se han revisado materiales interesantes. Actis (1998) refiere los proyectos áulicos desarrollados en el bachillerato argentino, que se conoce con el nombre de polimodal, donde se impulsa de manera conjunta los talleres de lectura, escritura y de narración oral. Asimismo Alvarado (2007) proporciona una serie de consejos prácticos para el fomento de la actividad lectora. Uno de ellos es el manejo adecuado del lenguaje no sólo por parte del facilitador sino también en los materiales de lectura con los que se trabajará. Más adelante, Bellorín y Martínez (2OIO) presentan una iniciativa para desarrollar un proyecto comunitario de promoción de la lectura. De manera sencilla explican los pasos básicos para llevar a cabo la propuesta. Los consejos van dirigidos al promotor para que no olvide que no sólo debe mediar entre los libros y las personas, sino también entre los contenidos técnicos que ocupa el taller y los saberes que ya tienen los participantes. Borunda Olivas y Almeida Uranga (2OIO) realizan un estudio exploratorio de los procesos de lecto-escritura en salas de lectura del nivel medio superior en doce municipios de Chihuahua. Las salas estaban ubicadas en zonas campesinas, en ambientes interculturales e inter-lingüísticos, con lectores de hablas originales y mestiza y en ambientes urbano-juveniles.

En el contexto nacional surge el Programa de Fomento a la Lectura para la Educación Media Superior (SEP, 2OII). La estructura del documento se integra por cuatro componentes principales: dotación de acervos bibliográficos e infraestructura para espacios de lectura, estrategias de fomento de la lectura y escritura, formación de mediadores y estrategias de comunicación social. Dentro del segundo componente destacan dos líneas de acción: estrategias para el desarrollo de competencias lectoras en el aula y la escuela, así como el fomento de la lectura desde las asignaturas.

Desde otro punto de vista, Garrido (2OI2) postula que lectura y escritura son dos actividades inseparables. El facilitador de un taller de lectura no debe olvidar esta realidad cuando planea sus actividades para que los asistentes las realicen, pero antes que nada, un buen promotor tiene que ser un buen lector autónomo y ejercitarse en la escritura. En otras palabras el promotor debe predicar con el ejemplo ante su público.

En el ámbito educativo venezolano, Cegarra Soto (2OI4) reporta un exitoso programa denominado Encuentros locales de las letras trujillanas, impulsado por el Gobierno del Estado de Trujillo y que tiene como sede el Liceo "Ramón Ignacio Méndez". El programa atiende a ciento cincuenta estudiantes de seis grupos de los tres años del bachillerato. Se ofrecen talleres de promoción y creación literaria, en los cuales los jóvenes leen obras de autores venezolanos y escriben materiales literarios diversos como: narrativas breves, poemas y canciones de rap. La finalidad del programa es acercar a los adolescentes a la lectura y la publicación de los textos escritos por los participantes en el taller.

Por su parte, el Programa Universitario de Fomento a la Lectura Universo de Letras (UNAM, 20I4) propone entre otras actividades, el Círculo de letras: cómo no te voy a leer. Lo que éste propone es la creación de círculos de letras itinerantes en cada una de las escuelas, facultades, preparatorias y planteles del CCH, con un máximo de cien 
títulos por biblioteca, que una vez cada quince días den servicio a su comunidad. El objetivo fundamental es que los alumnos puedan tomar y llevarse el libro que deseen, con la única condición de que donen otro. De esta forma se garantiza la circulación permanente de títulos, temas y autores. Para ello, se ofrece un curso de capacitación para alumnos voluntarios que administran los acervos que integran los círculos de lectura.

Asimismo cabe hacer mención que la Dirección General de Bachillerato del Estado de Veracruz, en los últimos seis años, ha implementado tres programas de lectura: Desarrollo de microhabilidades de lectura de comprensión, para primer y segundo semestre, pretende favorecer en los estudiantes la competencia de lectura en el nivel de comprensión, a través de actividades que posibiliten la práctica y adquisición de cada una de las microhabilidades de lectura. Fomento de la lectura, para tercer y cuarto semestre, busca promover el hábito de la lectura a través de la estrategia: círculos de lectura. Programa Estatal de Lectura para Educación Media Superior (PRELEMSyS), para quinto y sexto semestre, tiene como propósito elevar el nivel de dominio de la competencia lectora en los alumnos de educación media superior y superior, para que sean capaces de comprender, emplear y reflexionar acerca de textos escritos con interés, potenciar su desarrollo personal para el logro de metas y participar de manera activa en la sociedad.

\section{Una nota sobre fundamentos teóricos}

El marco teórico propuesto para abordar a la literatura tradicional considera dos grupos de disciplinas: las interesadas de manera directa en el tema y las de apoyo. En el primer ámbito destacan: los estudios del folklore, la semiología, la teoría de los géneros literarios y los estudios propios de literatura tradicional. El segundo sector está integrado por la teoría de la reproducción, los tres estados del capital cultural, la concepción sociocultural de la lectura, el enfoque regional en antropología y la teoría de la creatividad.

De manera general se podría decir que los estudios del folklore se ocupan de los distintos aspectos de la cultura de cualquier pueblo, incluida la literatura tradicional: versos, mitos, leyendas. Sin embargo, Aretz (i988) aclara: "lo folklórico, en cambio, es lo tradicional, lo que tiene larga trayectoria, lo que es propio del pueblo desde varias generaciones" (p. 19). En este sentido la literatura tradicional subsiste por transmisión oral de una generación a otra. Igualmente Aretz (I988) propone una clasificación del folklore: el material o ergológico, el social y el espiritual-mental. El folklore material o ergológico incluye todo lo que corresponde a objetos: vivienda, mobiliario, enseres domésticos, indumentaria, medios de transporte, etc. El folklore social estudia los diversos aspectos que atañen a la vida de relación de las personas, desde las formas típicas del lenguaje hasta los usos y costumbres, comprendiendo fiestas, ceremonias y juegos. El folklore espiritual-mental se ocupa del producto intangible de la mente del hombre: manifestaciones artísticas (literatura popular, música, danzas, artes plásticas), los diferentes aspectos del saber popular y las creencias y ritos (devociones populares y supersticiones). De este 
modo, la literatura tradicional está incluida dentro del llamado folklore espiritual-mental. En el proyecto de intervención se utilizaron mitos, leyendas y cuentos populares como materiales de lectura, mismos que pertenecen a la narrativa tradicional mexicana.

Pierre Guiraud (1982) distingue tres tipos de códigos: lógicos, estéticos y sociales. En el estudio pormenorizado de los códigos estéticos, el autor explica que el término estético es el modo de expresión de las artes y de las literaturas. Guiraud (I982) sostiene que la experiencia afectiva o estética: “corresponde al sentimiento íntimo y puramente subjetivo que emite el alma frente a la realidad” (p. 87). Las artes son representaciones de la naturaleza y de la sociedad, representaciones que pueden ser reales o imaginarias. Las literaturas son artes del lenguaje y crean objetos lingüísticos significantes. Para este especialista, las artes y literaturas populares y folklóricas interesan profundamente a la semiología en la medida en que expresan situaciones arcaicas, simples y universales. Los argumentos de Guiraud resultaron significativos para el proyecto de intervención en la medida en que se pretendió favorecer una lectura recreativa de textos narrativos tradicionales, donde el lector tuvo una experiencia afectiva o estética al entrar en contacto con estas narraciones tan apreciadas para los estudios semiológicos.

La teoría de los géneros literarios considera en sus distintas clasificaciones a los géneros de la literatura tradicional. García Berrio y Huerta Calvo (r995) incluyen un apartado dentro de la tipología de los géneros poético-líricos para el estudio de las formas populares de la lírica tradicional: canción, villancico, jarcha, seguidilla, romance y balada. En la tipología de los géneros épico-narrativos, los autores se refieren al cuento folklórico y al cuento literario, también mencionan al mito y a la leyenda enfatizando su carácter oral. García Berrio y Huerta Calvo (I995) explican que la oralidad pone de relieve géneros de condición simple como el mito, el cual es un recuerdo no personal sino colectivo y sus temas son los fundamentales en la concepción del mundo, los orígenes del universo, la presencia de la muerte, etc. Por último, en la tipología de los géneros didáctico-ensayísticos ubican al refrán en relación con los estudios del folklore. Así el hecho de que la teoría de los géneros literarios abarque en sus distintas tipologías a los géneros propios de la literatura tradicional es de suma importancia para el proyecto de intervención, porque es un sólido argumento para explicar que la literatura de transmisión oral no es una manifestación cultural de segunda categoría y que por lo tanto merece un sitio especial en los programas de estudio de los niveles básico y medio.

Los estudios particulares sobre literatura tradicional son numerosos. Propp en su libro Morfología del cuento (I928) reduce todos los relatos folklóricos a siete esferas de acción: el agresor, el donante, el ayudante, la princesa u objeto buscado, el mandatario, el héroe y el falso héroe. Al mismo tiempo distingue en los cuentos treinta y un elementos fijos o funciones. Por su parte, Vansina ha aportado su valiosa clasificación de los textos orales tradicionales. La tipología de Vansina (I966) distingue cinco categorías: las fórmulas, la poesía, las listas, los relatos y los comentarios. Dentro de los relatos se ubican los mitos, las leyendas y los cuentos populares. En México, Carlos Montemayor (I999) ha creado una clasificación de los cuentos de tradición oral en las lenguas indígenas con el 
propósito de facilitar el análisis formal de los relatos. El conjunto de estos estudios es un referente obligado para el interesado en adentrarse al ámbito de la literatura tradicional, particularmente a la narrativa. En el proyecto de intervención sólo fueron utilizadas las clasificaciones de Vansina y de Montemayor, las cuales facilitaron el manejo correcto de los nombres de las narraciones tradicionales que los alumnos leyeron en las sesiones del taller, así también resultaron útiles para el diseño del cuestionario inicial en donde los educandos expresaron sus preferencias temáticas en relación con los mitos, las leyendas y los cuentos populares.

La teoría de la reproducción nace a principios de los años setenta del siglo XX. Sus creadores son los franceses Pierre Bourdieu y Jean Claude Passeron, quienes publicaron su libro La reproducción, en I970. Aunque la teoría de la reproducción pertenece al campo de la sociología, también se ha ocupado para revisar los procesos educativos. Figueroa de Katra y Pino Méndez (I999) sostienen que una de las ideas centrales de esta teoría es que la escuela como institución social reproduce en sus adentros, a través de los programas, los maestros y los directivos, los aspectos principales de la cultura dominante. Ésta pertenece a los grupos que en la sociedad actual tienen el control del poder económico y político. Así, el Estado y los grupos dirigentes forman a los individuos conforme a determinadas pautas y valores. En este sentido, la teoría de la reproducción ha puesto al descubierto que la educación -en términos sociales, políticos e ideológicos- es un instrumento de dominación. Los argumentos de la teoría de la reproducción permitieron explicar el hecho de que los programas de estudio de Literatura y de Taller de lectura y redacción en el bachillerato se rijan por un estricto canon literario y que la literatura tradicional ocupe un lugar incidental dentro del actual curriculum del nivel medio superior.

Bourdieu acuñó el concepto de capital cultural. Se trata de una unidad de medida para saber la cultura que posee una persona. En este orden de ideas, Bourdieu habla de los tres estados del capital cultural: estado incorporado, estado objetivado y estado institucionalizado. El primero de ellos tiene que ver con un largo proceso de adquisición. Se trata de inversiones personales de tiempo, que implican esfuerzo y costo. Es un patrimonio del individuo que no se puede heredar, pues sólo a él pertenece. El segundo está relacionado con los objetos culturales. Bourdieu (I979) explica que el capital cultural objetivado en apoyos materiales -escritos, pinturas, monumentos, etc.-, es transmisible en su materialidad. Los objetos culturales son considerados inversiones. También se requiere cierto conocimiento para poder adquirirlos. El tercero se vincula con la posesión de títulos, documentos y diplomas que una persona puede llegar a obtener a lo largo de su vida. El estado institucionalizado del capital cultural es medible tanto en cantidad como en calidad. El concepto de capital cultural de Bourdieu resultó útil para el diseño de los cuestionarios y la entrevista semiestructurada que se aplicaron en el proyecto de intervención, así como en la caracterización de los padres de los participantes en el taller.

Algunos autores, entre ellos Chartier, Garrido y Cassany, se refieren a la lectura desde una perspectiva sociocultural. De esta manera, Chartier (20o6) expresa que todo lector pertenece a una comunidad de interpretación, misma que posee normas, reglas, 
convenciones y códigos de lectura propios. Por su parte, Garrido (2OI2) sostiene que la lectura y la escritura son productos sociales en donde culminan las culturas. La lectura y la escritura son actos comunicativos que se realizan en sociedad, aunque a veces esto no se perciba.

Cassany (2006) habla de una concepción sociocultural de la lectura. El autor sostiene que todo discurso refleja una visión del mundo. Cada comunidad, cada ámbito y cada institución usan el discurso de modo particular, según su identidad y su historia. Para un estudiante que no tiene el hábito de la lectura será mucho más accesible iniciarse en esta práctica con materiales que resultan cercanos a él porque provienen de su mismo contexto cultural. Esta es una buena razón para justificar el por qué se emplearon ejemplos representativos de la narrativa tradicional mexicana en el proyecto. La concepción sociocultural entiende a la lectura como una práctica insertada en una comunidad particular, que posee una historia, una tradición, unos hábitos y unas prácticas comunicativas especiales. En este sentido, Cassany (2006) afirma: "aprender a leer requiere conocer estas particularidades, propias de cada comunidad” (p. 38). La concepción sociocultural de la lectura describe las maneras de usar la lectura de cada comunidad, donde las palabras y las expresiones cargan con las connotaciones culturales de cada lugar. Según Cassany (2009) esta orientación sobre la lectura sugiere que leer y escribir suponen participar en prácticas letradas establecidas, en transacciones sociales que usan textos escritos.

Otro de los elementos teóricos con que cuenta este trabajo es el que se refiere al enfoque regional en antropología que se dio a conocer en México a partir de la influencia de Franz Boas y su discípulo Manuel Gamio. La población del Valle de Teotihuacán (I922) es considerada, en este sentido, la obra cumbre de Gamio. La antropología mexicana ha realizado aportaciones valiosas desde los enfoques regionales. Un caso memorable fue el llamado Proyecto Tarasco de los años setenta del siglo XX. Éste se caracterizó por trabajar con un equipo interdisciplinario y su área de estudio se delimitó en función de lo que había sido el territorio del imperio tarasco. El enfoque regional ha brindado múltiples oportunidades de estudio a geógrafos, historiadores y antropólogos, pero también diversas disciplinas, incluida la literatura tradicional, contribuyen de manera evidente a plantear y esclarecer la problemática regional. Según Ibarra Valenciana (20I4) un área cultural se refiere a un "determinado grupo de personas que se encuentran en una región definida y que comparten características culturales comunes” (p. 27). Ejemplos de áreas socioculturales pueden ser un estado, unos municipios, una nación o un territorio dependiente, cuyos habitantes están unidos por la legislación, por las relaciones socioeconómicas, costumbres y tradiciones comunes. El proyecto de intervención que se presenta recuperó el concepto de área cultural ya que los estudiantes se dieron a la tarea de rescatar leyendas provenientes de sus núcleos familiares insertados en cuatro municipios veracruzanos: Xalapa, Las Vigas, Alto Lucero y Naranjos Amatlán, así como la Ciudad de México. Cabe hacer aquí la aclaración que las leyendas recuperadas por los educandos son solamente versiones que se cuentan en sus municipios de origen, no se afirma que las historias hayan iniciado en esos lugares porque para ello se necesitaría hacer un rastreo 
de las rutas culturales que han seguido estos relatos durante siglos. Lo mismo puede decirse de la leyenda que procede de la Ciudad de México.

Desde el punto de vista psicológico, se considera el discurso de Joy Paul Guilford, frente a la Asociación Americana de Psicología en r95o, como punto de partida al estudio riguroso e independiente de la creatividad. El psicólogo norteamericano construyó una teoría sólida y consistente sobre la creatividad a través de distintas publicaciones entre I959 y r975. El modelo de Guilford obtiene ciento veinte aptitudes que conforman la estructura intelectual del sujeto de las que la fluidez, flexibilidad, originalidad y elaboración son las que definen y caracterizan el pensamiento creativo de un individuo.

Según la revisión hecha por Carevic (2006), para Guilford la creatividad significa salir de lo obvio, lo seguro y lo previsible para ocasionar algo que sea novedoso. El autor plantea que la creatividad no es el don de unos pocos, sino una propiedad compartida por todos los seres humanos en mayor o menor grado. Guilford propone un listado de seis habilidades que se hallan presentes en los individuos creativos: fluidez, sensibilidad a los problemas, originalidad, flexibilidad, elaboración y capacidad de redefinición. Las habilidades del individuo creativo esbozadas por Guilford permitieron valorar los dibujos y las tiras cómicas elaborados por los alumnos durante las sesiones del taller de lectura de textos narrativos tradicionales.

De este modo se presentó una breve descripción de las distintas disciplinas que de una manera u otra contribuyen a presentar el marco teórico de la literatura tradicional. Un primer grupo tiene un impacto directo en esta temática y un segundo ámbito de teorías sirve como apoyo para la implementación del proyecto de intervención.

\section{Contexto, problema de intervención y objetivos}

La lectura en el nivel medio superior se realiza con fines utilitarios. El adolescente está acostumbrado a leer para contestar un cuestionario o preparar un organizador gráfico sobre algún contenido en particular. En los libros de texto de la materia de Literatura la situación no varía, los textos vienen acompañados por una guía de lectura en el mejor de los casos, la cual deberá resolver el alumno después de haber leído el material en cuestión. Si el docente de la clase de Literatura se limita a repetir este patrón provocará en los estudiantes un rechazo paulatino hacia la actividad lectora. Del mismo modo si el profesor de Literatura recibe de manera pasiva el programa de estudio de la asignatura sin hacer adecuaciones pertinentes al mismo, se corre el peligro de mostrar al público bachiller una concepción errónea de la literatura y de limitarlo a una práctica lectora deficiente. El educando concluirá su bachillerato despreciando la literatura y sin querer saber nada de la lectura. En este sentido Paredes Chavarría (I995) comenta que el alumno cuando lee por imposición termina vacunado contra la lectura literaria.

En los últimos tres ciclos escolares he sido docente de la clase de Literatura en la Escuela de Bachilleres Modalidad Mixta Veracruz, ubicada en la ciudad de Xalapa. Es una 
institución particular, incorporada a la Dirección General de Bachillerato, que se caracteriza por tener grupos pequeños de primero a sexto semestre. La población estudiantil está integrada por jóvenes repetidores que buscan una alternativa para concluir su bachillerato, por algunas amas de casa que han regresado a la escuela después de varios años de ausencia y por adolescentes que laboran de lunes a viernes y no tienen otra opción para seguir estudiando que hacerlo los sábados. Hasta el momento los grupos con los que he trabajado la materia de Literatura han sido pequeños: diez alumnos en promedio. La práctica lectora de estos muchachos se caracteriza porque sólo leen una novela o un cuento si uno se los encarga de tarea, las obras incluidas en el libro de texto oficial no resultan significativas para ellos, pero en clase se muestran un tanto interesados cuando les ofrezco materiales diferentes a los propuestos en su libro de texto. Esto lo he llevado a cabo en Literatura I cuando les proporciono mitos y leyendas como parte de los contenidos señalados para la primera unidad que se titula: Textos narrativos breves, y he tenido una respuesta similar cuando he incorporado ejemplos de cuentos populares para ser leídos en clase, aunque el programa de estudio de la asignatura en la segunda unidad denominada: El cuento, sólo contempla la lectura de cuentos literarios pertenecientes a un canon de autores decimonónicos y contemporáneos. A partir de todo lo anterior organicé un taller donde se promovió una lectura recreativa de narraciones tradicionales, a manera de complemento del programa de estudios de Literatura I, donde los asistentes tuvieron la posibilidad de leer los textos que fueran de su agrado, utilizando diversas estrategias de promoción para llevarlos a una experiencia de lectura placentera y contribuir como ha expresado Lerner (2OOI) a la formación de una comunidad de lectores en la escuela.

El objetivo general del proyecto de intervención fue contribuir a la formación de lectores que puedan distinguir géneros discursivos, valores, connotaciones de las palabras y utilicen los elementos del código escrito en textos breves a partir de una lectura recreativa de narraciones tradicionales mexicanas, en un grupo de la Escuela mencionada. Los objetivos particulares fueron cinco: (I) Coadyuvar para que se logre la distinción de los rasgos genéricos y la clasificación del mito; (2) Contribuir a la identificación de los recursos expresivos del lenguaje de la leyenda; (3) Propiciar la identificación de los valores sugeridos en la trama del cuento popular; (4) Promover la creatividad del estudiante para el diseño de textos que combinan imágenes y palabras, y (5) Favorecer la expresión escrita a partir de la lectura.

\section{Metodología}

El proyecto de intervención se efectuó en la Escuela de Bachilleres Modalidad Mixta Veracruz, de la ciudad de Xalapa, Veracruz, incorporada a la Dirección General de Bachillerato del Estado de Veracruz. Se trabajó con el grupo de primer semestre con dos alumnos; un tercer estudiante sólo participó en las tres primeras sesiones del taller. Es necesario puntualizar que las sesiones del taller incluyeron diversas actividades tratando 
de buscar un sano equilibrio en la distribución de las mismas. Además de que hubo momentos dedicados a la lectura de textos narrativos tradicionales, en los cuales se implementaron estrategias específicas, también hubo minutos destinados a la recopilación de datos por medio de la aplicación de cuestionarios, entrevistas y actividades que sirvieron para valorar la apropiación que tuvieron los lectores de los contenidos de las narraciones propuestas como materiales de lectura para el taller. La intervención se desarrolló en un total de ocho sesiones de una hora durante los cuatro sábados de noviembre y los dos primeros sábados de diciembre de 20I5, el tercer sábado de enero y el tercer sábado de febrero de 20I6. Las dos últimas sesiones se tuvieron que programar hasta enero y febrero de 2016 por diferentes razones: Es importante mencionar que de las ocho sesiones del taller las primeras siete tuvieron lugar en el salón de primer semestre, un recinto amplio, con mobiliario apropiado y una buena acústica; mientras que la última se verificó en el salón audiovisual de la institución.

Dentro de los recursos materiales se contó con una antología de textos narrativos tradicionales, que fue el fruto de una búsqueda de distintos materiales de lectura en múltiples fuentes. También se incluyeron varios artículos de papelería: cartulina, papel kraft, hojas de colores, crayolas, pinturas de madera, plumones, tijeras, lápiz adhesivo y durex. Por otro lado, los equipos técnicos que se ocuparon en el desarrollo del taller fueron: laptop, cañón, grabadora y cámara fotográfica.

En el proyecto se utilizaron cuatro instrumentos para recoger datos: cuestionario, entrevista semiestructurada, bitácora y portafolio de evidencias. El cuestionario inicial se aplicó en la primera sesión del taller con la finalidad de recabar datos generales de los participantes y conocer sus temáticas preferidas en lo que se refiere a los textos narrativos tradicionales. Gracias a la información obtenida con este instrumento pude integrar una pequeña antología de mitos, leyendas y cuentos populares seleccionados de acuerdo con los gustos de los alumnos y que me servirían como materiales de lectura para las siguientes sesiones del taller. Posteriormente se aplicó un cuestionario inicial modificado para averiguar el contacto previo de los jóvenes con las narraciones tradicionales en el núcleo familiar y en la escuela. El cuestionario final se aplicó en la penúltima sesión del taller con el propósito de indagar el punto de vista de los jóvenes con respecto de las estrategias de promoción de la lectura implementadas en la intervención, también se pretende saber si las sesiones del taller contribuyeron para que los estudiantes alcanzaran los objetivos propuestos en el proyecto. La entrevista semiestructurada se realizó del mismo modo en la penúltima sesión del taller. A través de la entrevista se exploran los antecedentes lectores de los alumnos en relación con la narrativa tradicional tanto en la familia como en la escuela, asimismo se pretende conocer el impacto del taller en la vida de los estudiantes. Con los cuestionarios y la entrevista semiestructurada se siguió un ciclo completo: diseño de formato, impresión y fotocopiado antes de ser aplicados a los participantes del taller, y la revisión y análisis posterior de los datos obtenidos. Del mismo modo con los cuestionarios y la entrevista se partió del supuesto de que los alumnos respondieran con veracidad en todo momento. Con el uso de la bitácora se logró un registro puntual de los 
incidentes ocurridos en cada sesión. La redacción de la bitácora se llevó a cabo el mismo día en que se realizaron las actividades procurando anotar el tiempo que ocuparon los alumnos para efectuar cada una de ellas. La bitácora resultó útil para analizar e interpretar los datos anotados de manera posterior, durante la redacción del informe de la intervención. Asimismo el portafolio de evidencias reunió las distintas actividades hechas por los jóvenes durante las sesiones del taller. Cabe aclarar que la entrega de la totalidad de actividades se verificó en tiempo y forma por parte de los participantes. El portafolio de evidencias ayudó a valorar el avance lector de cada educando, así como sus percepciones sobre los textos leídos y su participación en las estrategias implementadas.

Debido a que el número de participantes en el taller sólo fue de dos estudiantes y de que los datos obtenidos a través de los distintos instrumentos expresan sobre todo cualidades y no cantidades se propuso una estrategia de análisis con un carácter descriptivo. Hernández Sampieri, Fernández Collado y Baptista Lucio (2007) sostienen que los estudios descriptivos se centran en recolectar datos que muestren un evento, una comunidad, un fenómeno, hecho, contexto o situación que ocurre, en sus diferentes aspectos. De este modo, se llevó a cabo una revisión minuciosa de los resultados arrojados por los cuestionarios de inicio y término, así como de la entrevista semiestructurada. Para facilitar la interpretación de los resultados se optó por unificar el cuestionario inicial y el cuestionario inicial modificado. También se fusionaron el cuestionario final y la entrevista semiestructurada. Se tomó esta decisión para eliminar aquellos reactivos presentes en los instrumentos originales que eran irrelevantes y se optó por recuperar y conservar los reactivos altamente significativos.

A partir de ahí se procuró establecer comparaciones entre las respuestas de las dos participantes considerando lo expresado en la hipótesis de intervención, el objetivo general y los objetivos particulares. Asimismo para exponer los resultados se recurrió al uso de tablas comparativas y de nubes de palabras. Las primeras permiten identificar semejanzas y diferencias de dos o más objetos o eventos, presentan información de forma breve y son fáciles de leer y entender. Por su parte, una nube de palabras es una representación visual de las palabras que conforman un texto, en donde el tamaño es mayor para las palabras que aparecen con más frecuencia. Las nubes de palabras poseen múltiples usos educativos, pero en este caso particular se ocuparon para mostrar los resultados de una actividad de prelectura cuando las participantes seleccionaron, en la primera sesión del taller, las temáticas de su preferencia con respecto de los mitos, las leyendas y los cuentos populares. Cabe aclarar que las tablas comparativas fueron elaboradas en Word, mientras que las nubes de palabras se crearon gracias a la aplicación de Image Chef que permite hacer un mosaico de palabras y que es de fácil acceso en la página www.imagechef.com/ic/es/word_mosaic/ 


\section{Implementación de la estrategia de intervención}

Es importante aclarar que mucho antes de la primera sesión del taller que sirvió para realizar el diagnóstico del grupo y diseñar la estrategia, el día I de octubre de 2015 me reuní con la directora de la Escuela para presentarle un cronograma de las actividades que incluiría el taller de lectura, el cual fue revisado minuciosamente por ella antes de darme su visto bueno. Asimismo acordé con ella el periodo, el horario y el sitio en que se llevarían a cabo las sesiones del taller: los sábados de ıı:оo a ı2:30, en el salón de primer semestre, a partir del primer sábado de noviembre de 20I5 hasta el tercer sábado de febrero de 20I6. La directora puso a mi disposición el equipo técnico de la escuela: grabadora, cañón y laptop. También dio instrucciones al personal administrativo y al grupo de asesores para que me apoyaran en todo lo que hiciera falta.

A partir del día i de octubre de 20I5, empecé a preparar los materiales de lectura y los artículos de papelería que ocuparía en el taller. También decidí a qué adultos mayores podría invitar para que vinieran a contar una leyenda a los alumnos y me puse en contacto con dos maestros normalistas para que participaran como cuentacuentos en una de las sesiones del taller.

Cuando pensé en el diseño del taller de lectura de narrativa tradicional de México, quise incluir de manera equitativa ejemplos de mitos, leyendas y cuentos populares para presentar un panorama general de este tipo de relatos a los participantes en las sesiones del taller. Cuando elaboré mi cronograma de actividades tuve que descartar las sesiones: uno, siete y ocho porque en las dos primeras tendría que aplicar cuestionarios y hacer la entrevista, mientras que en la última montaría una exposición de dibujos y tiras cómicas -creados por los estudiantes a partir de la lectura del mito de El origen del maíz y la leyenda de La mulata de Córdoba-, así como también presentaría ante la comunidad educativa la antología de leyendas recopiladas por los alumnos del taller. De tal manera que sólo contaba con cinco sesiones sabatinas para lograr este fin. Asigné la sesión número dos para abordar el mito; las sesiones tres y cuatro para trabajar con la leyenda; por último, las sesiones cinco y seis estarían dedicadas para ahondar en los pormenores del cuento popular.

La siguiente interrogante que se me presentó fue ¿qué materiales de lectura ocuparía para las sesiones del taller? Aquí es importante decir que las respuestas del cuestionario inicial sobre preferencias temáticas en relación con mito, leyenda y cuento popular orientaron mi búsqueda de textos dentro de la experiencia educativa de Cartografías lectoras en el primer semestre de la especialización. Se tuvo el cuidado de elegir materiales de buena calidad provenientes de antologías publicadas por el Fondo de Cultura Económica: Krickeberg (2OI4) y Morábito (2OI4); el Instituto Politécnico Nacional: Jiménez Arreola (2005) y el Archivo General del Estado de Nuevo León: Villanueva de Cavazos (I988). Los ejemplos de relatos que se leyeron en el taller tuvieron esta procedencia. Para el diseño de las actividades de inicio y término de cada tipo de narración tradicional también se procuró seleccionar textos de las fuentes antes mencionadas aunque hubo 
algunas excepciones. Tal es el caso de las leyendas que debían contener en su lenguaje ejemplos de topónimos y de palabras derivadas del náhuatl, por lo que se tuvo que recurrir a una antología publicada por el Ayuntamiento de Xalapa: Espejo (I99I). Igualmente para las lecturas gratuitas con las que se iniciaba cada sesión me vi en la necesidad de utilizar textos provenientes de otras fuentes como por ejemplo un número especial de la Revista de la Facultad de Letras de la Universidad Veracruzana que se dedicó a la literatura tradicional en los meses de julio - diciembre de r99ı.

\section{Resultados y discusión}

Los ámbitos familiar y escolar son unos antecedentes importantes para determinar el grado de cercanía que tuvieron las participantes con las narraciones tradicionales leídas en el taller. Por lo que se refiere a la familia es necesario expresar lo siguiente. La escolaridad de ambos padres de la alumna de cuarenta y cuatro años es de primaria y secundaria. Con respecto de la joven de veintitrés años, la escolaridad de la madre es primaria y la del padre es secundaria. En adelante me referiré a la alumna de cuarenta y cuatro años como At y a la estudiante de veintitrés años como A2. Asimismo mientras AI expresó que ninguno de sus padres fomentó en ella el hábito de la lectura, A2 dijo que su madre sí fomentó en ella el hábito de la lectura. Igualmente As señaló que en la casa paterna no había libros de narraciones tradicionales. A2 declaró que en la casa paterna sí había libros de relatos tradicionales. De la misma manera, Aı comentó que en su familia tanto los abuelos, los padres y el suegro le leyeron o contaron narraciones tradicionales. A2 afirmó que los abuelos y las hermanas le leyeron o contaron relatos tradicionales. Sin embargo, A2 recordó mayor número de títulos de estos textos que le fueron leídos o contados en su contexto familiar, con respecto de Ai que mencionó un menor número.

En relación con la escuela, ambas mujeres realizaron sus estudios de primaria y secundaria en escuelas públicas de la ciudad de Xalapa. As estudió en la primaria Juan de la Luz Enríquez y la secundaria en la Federal No. 4; A2 estudió en la primaria Francisco I. Madero y la secundaria en la José Mancisidor. Ambas mujeres coincidieron al decir que fue en la primaria donde abordaron el tema de las narraciones tradicionales con mayor profundidad y también donde más leyeron este tipo de materiales. Nuevamente es A2 quien recordó mayor número de títulos de relatos tradicionales leídos en los niveles educativos previos.

Como complemento de los datos anteriores debe mencionarse que las dos mujeres expresaron que sí les gusta leer narraciones tradicionales, aunque sólo lo hacen a veces. En relación con el tipo de relato que es de su preferencia las dos señalaron que es la leyenda, pero Ai comentó que también le agrada el mito. Por todo lo manifestado hasta aquí parece que sí existe un vínculo entre los contextos familiar y escolar de las participantes y su cercanía con los textos narrativos tradicionales que fueron los materiales de lectura en el taller. 
El haber aplicado actividades iniciales y finales relacionadas con el mito, la leyenda y el cuento popular me permitió valorar el desempeño que tuvieron las alumnas en las sesiones del taller tomando como parámetros ciertas particularidades trabajadas en cada tipo de narración.

Concluyo que con las evidencias de As sí tuvo un avance porque de no poder identificar el tipo de mito ni la totalidad de sus elementos en la actividad inicial, logró realizar ambas acciones con éxito en la actividad final. Asimismo no tuvo problema de principio a fin para localizar los topónimos en las leyendas leídas. Lo que sí se observó fue un ligero titubeo para identificar las palabras derivadas del náhuatl en la actividad de la leyenda que se aplicó al inicio, situación que se superó en la actividad final. Del mismo modo la alumna no tuvo ninguna dificultad para identificar los valores propuestos en la trama de los cuentos populares que se leyeron, de hecho en la actividad final la estudiante también mencionó un antivalor que se evidenciaba en el comportamiento de un personaje de un cuento. Por lo que se refiere a los comentarios escritos solicitados en las diferentes actividades se advierte una mayor coherencia en los textos a medida que fueron transcurriendo las sesiones del taller. Sin embargo, la extensión breve de las redacciones en su conjunto no varió.

Asimismo concluyo que con las evidencias de A2 sí tuvo un avance porque de no poder identificar el tipo de mito en la actividad inicial, lo logró hacer de manera acertada en la actividad final. No tuvo problema de principio a fin para localizar los distintos elementos del mito. Lo mismo sucedió con el subrayado de los topónimos y las palabras derivadas del náhuatl en las actividades de la leyenda que se aplicaron al principio y al final. La estudiante pudo mencionar los valores sugeridos en la trama de los cuentos populares en todo momento. En la actividad final del cuento popular distinguió un antivalor simbolizado por la conducta de un personaje. Así también la extensión de los diferentes comentarios escritos sobre las lecturas realizadas no varió, siempre fueron breves pero con la característica de estar bien construidos.

La teoría de la creatividad de Guilford me permitió valorar los dibujos y las tiras cómicas que realizaron los participantes del taller de lectura de narrativa tradicional para determinar en qué grado los jóvenes fueron creativos en este par de actividades implementadas.

Los alumnos elaboraron dibujos después de haber leído el mito de El origen del maíz. Cabe hacer la aclaración que en esta actividad sí participó el alumno varón de dieciséis años, al cual me referiré como A3. Las habilidades del individuo creativo según Guilford se presentaron en estos trabajos de la siguiente manera: Aı mostró una fluidez ideacional al relacionar siete pequeños dibujos en su cartulina. Se percibe una elaboración en el desarrollo de las ideas: con siete dibujos y con veintiún palabras representa la trama del mito. Utiliza dieciséis sustantivos, cuatro adjetivos y una preposición. Desde luego hay una capacidad de redefinición porque transforma el texto escrito del mito en un mapa mental. Por su parte, A2 demostró una fluidez ideacional al relacionar tres pequeños dibujos en su cartulina. Hay una elaboración en el desarrollo de las ideas: a partir de tres 
dibujos representa la trama del mito. Su capacidad de redefinición quedó evidenciada al haber logrado transformar el texto escrito del mito en un dibujo. Por último, A3 presentó una fluidez ideacional al relacionar dos pequeños dibujos en su cartulina. Asimismo se percibe una elaboración en el desarrollo de las ideas ya que con dos dibujos representa la trama del mito. La capacidad de redefinición la presenta A3 al transformar el texto escrito del mito en un dibujo.

Por lo que se refiere a las tiras cómicas elaboradas por las alumnas, después de haber leído la leyenda de La mulata de Córdoba, esto fue lo que se encontró: en la tira cómica de Ar se percibe una fluidez de expresión por la facilidad en la construcción de frases: se ocupan seis en toda la trama. También hay una elaboración en el desarrollo de las ideas: en cinco escenas condensa la trama de la leyenda. Asimismo se advierte una capacidad de redefinición porque la alumna logró transformar el texto escrito de la leyenda en una tira cómica. En el trabajo de A2 hay una fluidez de expresión por la facilidad en la construcción de frases: se ocupan cinco en toda la historia. Existe una elaboración en el desarrollo de las ideas: en cuatro escenas condensa la diégesis de la narración. Igualmente se percibe una capacidad de redefinición porque la joven transformó el texto escrito de la leyenda en una tira cómica.

Por todo lo expresado anteriormente y de acuerdo con los criterios de Guilford puede afirmarse que las dos participantes en el taller sí mostraron ciertas habilidades del individuo creativo, situación que se vio favorecida gracias al ambiente de libertad en que pudieron diseñar sus obras.

Las estudiantes además de leer en las sesiones del taller también escribieron. Además de los pequeños comentarios escritos que acompañaron a las actividades de las distintas narraciones tradicionales, las participantes escribieron a mano un par de leyendas. Este ejercicio de redacción fue el de mayor extensión durante la intervención. Las leyendas escritas a mano por Aı presentan las siguientes características: sólo utiliza letras mayúsculas, no coloca acentos y emplea únicamente comas y puntos de entre el conjunto de signos de puntuación. En cuanto a ortografía hay cierto titubeo para escribir el verbo llevaban, ya que utiliza la grafía v en la terminación -aban, asimismo el verbo hincarse lo pone sin h. Sin embargo, los dos textos tienen coherencia para relatar los sucesos acontecidos y no se advierte una repetición de vocablos. Las leyendas entregadas por A2 tienen estas características: utiliza minúsculas y mayúsculas, sólo coloca algunos acentos de todos aquellos que son necesarios y emplea tres signos de puntuación: coma, punto y guión. En la palabra advertencia se cambia la d por una b. En general, la letra es legible. Los dos textos son coherentes en la narración de los acontecimientos.

Puede concluirse que las leyendas escritas a mano por Ar y A2 si bien es cierto que evidencian limitaciones sobre todo en el ámbito ortográfico, logran cumplir con una intención comunicativa que en este caso es narrar de manera lógica una serie de sucesos ubicados en un tiempo y en un lugar determinado.

El trabajo realizado por las participantes en cada una de las sesiones del taller fue muy importante para lograr cumplir con los objetivos planteados en un inicio. Asimismo 
las estrategias empleadas para promover la lectura y la selección de las narraciones tradicionales que se leyeron en el taller causaron un impacto positivo en las estudiantes.

Con respecto de las estrategias utilizadas ambas alumnas tienen una valoración positiva de ellas. A Ar le agradó la visita de los adultos mayores para contar leyendas y la motivó a seguir leyendo este tipo de relatos en su tiempo libre. A A2 le gustó la visita de los cuentacuentos porque ella acostumbra leerle cuentos a su hijo. Del mismo modo las dos mujeres expresaron su visto bueno para los textos narrativos tradicionales que se leyeron. Ar dijo que estas narraciones le atraen porque le gusta saber de lugares, personas y animales, de dónde provienen y cómo viven. A2 expresó que estas historias te explican cosas bonitas e interesantes. Igualmente, ambas participantes coincidieron al decir que el taller las motivó para seguir leyendo estos relatos en los siguientes semestres del bachillerato. Ar puntualizó que para seguir conociendo más temas, mientras que A2 comentó que le llama la atención su lenguaje, el hecho de que expresan la cultura y las tradiciones de México. Otro aspecto que debe mencionarse es que las dos mujeres recordaron varios títulos de los relatos leídos en el taller lo que me indica que sí resultaron significativos para ellas.

El tipo de comentarios expresados por las estudiantes me hace pensar que tanto las estrategias implementadas en el taller para promocionar la lectura, como el tipo de textos que se leyó fueron los más pertinentes. Me agrada pensar que ambas alumnas se sintieron motivadas para seguir leyendo estas narraciones para sí mismas y para otros miembros de su familia como pueden ser los hijos.

\section{Conclusiones}

Hoy en día las escuelas del nivel medio superior deben enfrentar el reto de promocionar la lectura entre su alumnado. Esta tarea involucra a directivos, docentes y bibliotecarios, ya que se requiere de personal capacitado en esta disciplina que sea capaz de diseñar estrategias, elegir materiales de lectura que resulten atractivos para el público destinatario, tomando en cuenta las características propias de las modalidades escolarizada y mixta que existen hoy en día en los planteles pertenecientes a la Dirección General de Bachillerato del Estado de Veracruz. Gracias al trabajo desarrollado en ambas modalidades se atiende por igual a grupos de adolescentes, jóvenes y adultos, factor que debe considerarse cuando se pretende hacer promoción de la lectura.

Entre los principales resultados de la intervención aquí narrada se hallan los siguientes: logré que las dos alumnas participantes de principio a fin en esta experiencia, disfrutaran de la lectura en cada una de las sesiones, hicieran uso de su creatividad para el diseño de dibujos y tiras cómicas basados en el contenido de los textos leídos, así como también se dieron la oportunidad de escribir a partir de las diferentes lecturas efectuadas. Un indicador de estos logros fue el hecho de que las estudiantes expresaran su interés por seguir leyendo narraciones tradicionales en los siguientes semestres del bachillerato, 
y que hayan compartido los materiales de lectura, proporcionados en el taller, con sus familiares, especialmente con sus hijos. En este mismo contexto, gracias a las indagaciones que hicieron las participantes entre sus seres queridos, se logró integrar una antología de siete leyendas que fue presentada ante la comunidad educativa reunida con este fin.

Es a partir de mi experiencia como coordinador de este taller de lectura que puedo asegurar que los textos narrativos tradicionales resultan idóneos para promocionar la lectura en el bachillerato, además son un medio muy apropiado para ayudar a los lectores a reflexionar sobre los diversos aspectos que involucra la identidad cultural del mexicano, en momentos que sobre todo las generaciones jóvenes se ven inmersas en los desafíos que tiene un mundo globalizado. 


\section{Referencias bibliográficas}

- Actis, B. (1998). Literatura y escuela. Rosario: Homo Sapiens Ediciones.

-Alvarado, E. (2007). La importancia del lenguaje en el fomento a la lectura. México, D.F.: CONACULTA - Océano.

-Aretz, I. (I988). Manual del folklore. Caracas: Monte Ávila Editores.

- Bellorín, B., y Martínez, C. (2OIO). El ABC para desarrollar un proyecto comunitario. En B. Bellorín y C. Martínez, Comunidades lectoras. Guía para propiciar la lectura en su entorno (pp. Io-24). México, D.F.: CONACULTA.

- Borunda Olivas, G., y Almeida Uranga, R. (2010). Lectura y jóvenes en Chihuahua. Recuperado de http://www.uacj.mx/UEHS/Documents/CDi5.pdf

- Bourdieu, P. (I979). Los tres estados del capital cultural. Sociológica, 5, II - I7.

- Carevic, M. (2006). Creatividad. Recuperado de http: //www.psicologia-online.com/articulos/20o6/creatividad.shtml

- Cassany, D. (2006). Tras las líneas: sobre la lectura contemporánea. Barcelona: Anagrama.

- Cassany, D. (2009). Doce demos sobre la lectura. En D. Cassany, Para ser letrados. Voces y miradas sobre la lectura (pp. 37-62). Barcelona: Paidós.

- Castro, R. (2008). La intuición de leer, la intención de narrar. México, D.F.: Paidós.

- Cegarra Soto, V. (20I4). Encuentro de las letras continúa promoviendo la lectura. Recuperado de http://trujillo.gob.ve/index.php/component/content/article/8-noticias/...

- Chambers, A. (2007). El ambiente de la lectura. México, D.F.: Fondo de Cultura Económica.

- Chartier, R. (2006). Cultura escrita, literatura e historia (2a. ed.). México, D.F.: Fondo de Cultura Económica.

- Desarrollo de microhabilidades de lectura de comprensión. (s.f.). Xalapa, Ver.: Gobierno del Estado de Veracruz.

- Espejo, A. (Comp.) (г99I). Historias, cuentos y leyendas de Xalapa. Xalapa, Ver.: H. Ayuntamiento de Xalapa. 
- Espejo, A. (Comp.) (199I). Separata: Literatura tradicional y popular. Recopilación. Revista de la Facultad de Letras, 7, I - XII.

- Figueroa de Katra, L., y Pino Méndez, A. (I999). Teoría de la educación. Xalapa, Ver.: Secretaría de Educación y Cultura.

- Gambrell, L. B. (2007, August). Promoting pleasure Reading: The role of models, mentors, and motivators. Reading Today, p. I6.

- Gamio, M. (i979). La población del Valle de Teotihuacán. México, D.F.: Instituto Nacional Indigenista.

- García Berrio, A., y Huerta Calvo, J. (I995). Los géneros literarios: sistema e historia. (Una introducción) (2a. ed.). Madrid: Cátedra.

- Garrido, F. (20I2). Manual del buen promotor. Una guía para promover la lectura y la escritura. México, D.F.: CONACULTA.

- Gladwin, R., \& Goulding, A. (20I2). Recreational Reading in university libraries in The United Kingdom. New Review of Academic Librarianship, I8 (2), I4O - I64. doi: IO.IO80/I36I4533.20I2.709213.

• Guiraud, P. (1982). La semiología (9a.ed.). México, D.F.: Siglo Veintiuno Editores.

- Hanson, A. (2005). Telling stories in the school library. Knowledge Quest, 33 (5), 43-45.

- Hernández Sampieri, R., Fernández Collado, C., y Baptista Lucio, P. (2007). Fundamentos de metodología de la investigación. México, D.F.: Mc Graw Hill.

- Ibarra Valenciana, K. Y. (2OI4). Los relatos en el norte de Nuevo León: Un estudio de la tradición oral. Ciudad Juárez: Universidad Autónoma de Ciudad Juárez - Universidad Autónoma de Nuevo León.

- Jackson, M. (2007). Across the generations: Telling stories in Florida's libraries. Florida Libraries, 50 (I), I4 - I6.

- Jiménez Arreola, M. (Comp.) (2005). Leyendas de ayer, hoy y siempre. México, D.F.: Instituto Politécnico Nacional.

- Kohan, S. A. (i999). Disfrutar de la lectura. Barcelona: Plaza Janés.

- Krickeberg, W. (20I4). Mitos y leyendas de los aztecas, incas, mayas y muiscas. México, D.F.: Fondo de Cultura Económica. 
- Lerner, D. (20OI). Leer y escribir en la escuela: lo real, lo posible y lo necesario. México, D.F.: Fondo de Cultura Económica.

- Montemayor, C. (1999). Arte y trama en el cuento indígena. México, D.F.: Fondo de Cultura Económica.

- Morábito, F. (Comp.) (20I4). Cuentos populares mexicanos. México, D.F.: Fondo de Cultura Económica.

- Paredes Chavarría, E. A. (i995). La enseñanza - aprendizaje de la literatura en el bachillerato. Perfiles Educativos, 68, 49-5I.

- Programa de Fomento a la Lectura para la Educación Media Superior. (20II). Secretaría de Educación Pública. Recuperado de http: //www.dgb.sep.gob.mx/o4-m2/o2-programas/ siguele/FomentoLect.

- Programa Estatal de Lectura para Educación Media Superior y Superior. (s.f.). Xalapa, Ver.: Gobierno del Estado de Veracruz - Subsecretaría de Educación Media Superior y Superior.

- Programa Universitario de Fomento a la Lectura Universo de Letras. (2014). Universidad Nacional Autónoma de México. Recuperado de http: //www.pve.unam.mx/información/ cultura/universodeLetrasi4o8.pdf

- Propp, V. (1977). Morfología del cuento (3a. ed.). Madrid: Fundamentos.

- Sánchez Amador, M. P., Vázquez Martínez, A. A., Herrera Barreda, L., Herrera Ibarra, G., Olmedo Martínez, D., y Cid Garzón, L. (I994). Taller de lectura y redacción I. México, D.F.: Nueva Imagen.

- Vansina, J. (I966). La tradición oral. Barcelona: Labor.

- Villanueva de Cavazos, L. E. (Comp.) (i988). Leyendas de Nuevo León. Monterrey: Archivo General del Estado de Nuevo León. 